\title{
Fear of Losing the Mobile Phone Nomophobia among Students and Its Impact of Psycho-Loneliness and Learning in the Light of Some Variables
}

\author{
https://doi.org/10.3991/ijim.v14i16.12797 \\ Osamah (Mohammad Ameen) Aldalalah \\ Taibah University, Medina, Saudi Arabia \\ odalalah@taibahu.edu.sa
}

\begin{abstract}
The study aimed at detecting the level of nomophobia "No Mobile-phone Phobia" among students in Jordan and its impact on the psycho-loneliness. The sample of the study consisted of secondary school students in Jordan Irbid. The study used three Instruments: nomophobia scale, Psychometric Loneliness scale \& Interview Instrument. The findings showed that the level of nomophobia through smart phone applications among secondary school students was high. Further, the findings showed statistically significant differences between the averages of the students' estimates on the scale of nomophobia due to the gender variable for females; differences that can be ascribed to specialization in favor of scientific specialization and variable related to the impact of the school in favor of the students of public schools. Moreover, the findings showed a positive relationship between the averages of nomophobia and psycho-loneliness among students.
\end{abstract}

Keywords-Nomophobia, Mobile phone, Psycho-loneliness, Learning.

\section{Introduction}

Although there are general characteristics that psychologists are interested in studying and trying to lay down their theoretical foundations for the purpose of interpreting human behavior in a logical and organized framework, psychology considers that every human person has individual characteristics that distinguish it from others (Abreem, 2015). Because we live in a rapidly changing world with all its components: the cognitive explosion, scientific development, and information communication revolution that makes nations race among themselves to occupy an advanced position (Muflah, ElHersh, Ababneh, \&Aldalalah, 2010). This requires the provision of all elements of comprehensive public health, a fundamental element to keep pace with accelerating scientific developments (Bivin, Preeti, Parveen \& Thulasip, 2013). Therefore, enabling human beings to live in complete independence, is what mental health seeks through the achievement of psychological and social satisfaction and harmony to reach the learning that drives societies towards the track of development and prosperity; where the immense technical progress has become a feature of this era, in which the technology of 
the Internet invaded most public and official places as well as the individual's own places (Shatat, Aldalalah\&Ababneh, 2017). The world has become as a small village by crossing the temporal and spatial boundaries (Al Tarawneh\&Nafikh, 2012). The former generation derived their behavior data from the social, religious and moral legacy linked to the boundaries of the society in which they lived; however, today there are no limits or even restrictions; therefore, we must only admit that we encounter a challenge, we like it or not; as this amazing progress benefited humans to an extent that it might be harmful (Alkour, 2017).

Along with this tremendous and continuous technological progress, these devices are not only a means of communication, but their uses and applications are increasingly becoming a vital part of our modern world. Wireless communications in recent years have witnessed a tremendous technological leap forward from the era of digital telecommunications and mobile services which have strongly imposed themselves on all sectors of society, including the education sector (Dahshan, 2013). The use of Internetenabled communication has its psychological and functional benefits in everyday life. It has opened a new era of interaction among individuals of all ages as well as all classes of society (Shaheen, 2015). Thus, cellular and mobile networks have preceded all kinds of modern ICTs in reaching people, especially in developing countries. Further, the largest segment using this technology is the young who are the future and the pillars of development, progress and production in the world (Abu Mandi, 2016). Tavolacci, et al (2015) points out that this category (the young) uses the phone for very long periods of time; even, smartphones have become a part of the social culture among the young while engaging in the society and mingling with other people due to the services provided. $90 \%$ of people have their own phones and cannot stay without it. It is normal for people to hold their smartphones and take pictures of their surroundings or of themselves or to inspect these phones to keep up with events through various websites (AlAhmari, 2014).

Despite the positive aspects of mobile applications, overuse may negatively affect the mental health of users, especially the young, and may have an impact on the emergence of personal behavior in the study, ignoring the surrounding social environment, the emergence of withdrawal symptoms and lifestyle changes (Lee, Chang, Lin \& Chang, 2014). Technological development and progress are considered a source of psycho-loneliness and sometimes insecurity as the nature of human interaction in the age of modern technology weakened social links among members of society and deprived the individual of many elements of building a normal personality. Moreover, this allowed the spread of complex modes of social communication with others, such as the media and the internet, This causes the individual to acquire values that may violate his family's habits and lose the value and characteristics of his personality (Aldalalah, 2018). Psycho-loneliness leads to the individual's introversion and alienation from the people (Aitan, 2017). The attachment to technology is one of the main reasons that forces individuals to become psychologically lonely, after the harm caused by the misuse of communication technology and at the top of their pyramid are mobile phones through using these phones as platforms for entertainment and tampering through various social networking applications such as Facebook, Instagram and others (Ranaei, Taghavi \& Goodarzi, 2016). The study of Darcin, et al. (2016) confirms that the use of 
technological means of communication may affect the level of psycho-loneliness through the findings about the existence of a relationship between the use of smartphones and the sense of loneliness.

Nomophobia "No Mobile-phone Phobia" has emerged as a result of the increasing use of mobile phones, which is a condition that affects the individual with tension when he losing mobile phone, forgetting it at home or even not being connected to the Internet. It is a type of phobia. Many studies (Aparna, Bhavani, Maragatham 2017; Yildirim, 2015; Neelima, Pooja, Neha, Wavare 2015, Pavithra, Madhukumar, Murthy, 2015) have been concerned about this condition and its prevalence among students. They noted that the symptoms of the disease are: the inability to turn off the phone; obsessive inspection of emails, text messages and calls that are not responded to; constantly making sure that the battery is fully charged; and the inability to abandon the phone. Hence, came the idea of this study, condition (nomophobia) in the Jordanian environment, especially the young, represented by high school students, and to study its negative impact on the Jordanian population. With the numerousness and the spread of Internet networks and applications available and their wide use among the young and after the examination of many studies and research, including the study of Marakeshi (2014); Shaheen (2013), Neerab (2016); Darcin, et. al (2016); Aldalalah (2018) and other studies that showed a relationship between misusing these networks and applications and the sense of psycho-loneliness. In order to achieve the objectives of the study, it is sought to answer the following questions:

1. What is the degree of nomophobia in secondary school students in Jordan?.

2. Do the average scores of secondary school students in Jordan on the nomophobia scale differ according to student gender (male, female) the student's specialization (scientific, literary) and the type of school (private, government)?

3 . Is there a correlation between nomophobia and psycho-loneliness among high school students in Jordan?.

4. Is there an effect of nemphobia on Jordanian secondary school students learning?

This study aimed to determining the degree of nomophobia in secondary school students in Jordan. In addition, discover the difference between the average scores of secondary school students in Jordan on the nomophobia scale differ according to student gender (male, female) the student's specialization (scientific, literary) and the type of school (private, government). Show a correlation between nomophobia and psycholoneliness among high school students in Jordan. Finally, discover the effect of nemphobia on Jordanian secondary school students learning.

\section{The Theoretical Framework and Previous Studies}

\subsection{Nomophobia}

Nomophobia has emerged as a result of the modern technology revolution and its great development, as it defines nomophobia as the feeling resulted from losing the use of modern devices such as phones, tablets and computers that they are used to use 
(Yildirim\&Correia, 2015). Neelima, Pooja, Neha\&Wavare(2015) suggests that nomophobia is a person's fear of losing his or her phone, or being away from it or when it is closed.

Signs of a person suffering from phobia appear through behavior; Use of the phone constantly, and the inability to dispense with it wherever (Pavithra, Madhukumar, Murthy,2015); The person also having more than one phone as backup, for fear of losing one of them; feeling anxious and nervous as soon as he thinks that the phone is missing (Maulud, 2016; Dardera, 2016); or inability to use it due to lack of network coverage; failure to go to places where the phone is not allowed; checking the phone continuously if a new message or call arrives; keeping the phone open throughout the day and keeping it nearby while sleeping (King et al., 2014); lacking direct communication with others and preferring to communicate by telephone or social media; spending huge amounts of money on mobile phones and their usages; and the phone and its new applications becoming the focus of family and work talk (Holohan, 2015). Yildirim (2014) and Gezgin, Sumuer, Arslan \&Yildirim (2017) Have examined the state of nomophobia extensively. Yildirim divided it into four dimensions: the first dimension: Not being able to communicate. This dimension speaks of anxiety, fear and discomfort of being unable to communicate with friends, family members and individuals from outside the family; relying on means that enable individuals to communicate such as messages and calls. The second dimension is the loss of communication (losing connectivity), which is the individual feeling worried about the network been disconnected from the phone; the fear of not being unable to follow the factorial and local news because of the failure of social media such as Facebook; fear of being unable to communicate through email because of the Internet disconnection; and the inability to access Facebook and What's up due to the person's addiction to using them. The third dimension: not being able to access information. This dimension shows that the person is trying to get information in all ways, including mobile phone, which cannot be dispensed with at all times; therefore, the person is disturbed if he cannot get this information, or lose them from the phone, especially when needed; concern and fear increase if not being able to know and keep up with the news and developments all the time- such as the weather and other features of the applications available to them. The fourth and final dimension is giving up convenience, a feeling of anxiety, tension and discomfort when the battery is empty, which leads to inability to communicate with others. The individual gets the same feeling in the event of the disappearance of the signal of the network or the phone signal.

The cause of fear and anxiety in a person is the inability to constantly check the phone and communicate with others, because it is the cornerstone of his life. Despite these negative feelings, a person cannot live without his phone.

\subsection{Psycho-loneliness}

Psycho-loneliness is a situation in which the individual feels lonely and away from others, lacking love and caring for them, and unable to get rid of feelings of loneliness and isolation despite being among others (Zaqout, 2011). Sometimes, a person willingly isolates himself to concentrate on an idea or subject. The individual does not feel 
annoyed or stressed because of alone. Degree (2017) define loneliness as a person's dissatisfaction with the quality of relations with others, and feeling uncomfortable about these relations. Further, psycho-loneliness is the desire to distance oneself from others and to enjoy sitting apart from them, with the difficulty of being able to plead with them and the difficulty of adhering to them (Melhem, 2010) . Coupled with a person's feeling of lack of self-confidence and being unloved and incapable of entering into social relationships, It is also he prefers to be alone as long as possible.

In addition to the person feeling shy and tense in the presence of others and not interacting with them positively and reasonably; He is a person who does not trust himself (Wei, Russell \& Zakalik, 2005). Moreover, it is defined as a state in which person feels alienated from others and misunderstood by them, and unable to engage in deep relationships with others. This results in weariness and boredom when meeting the community in his surroundings (Vanhalst, 2012). Further, it is defined as a disturbance in the person's relations with the self and others, which puts him in a state isolation, leading to feelings of headache, fatigue, loss of appetite and sleep disturbance. This greatly affects his psychological and academic performance in general (Nuri\& Kohan, 2016).

The sense of psycho-loneliness is a condition experienced by the individual as a result of painful negative experiences lacking forms of affection, love and familiarity with others generated from a painful negative experience that generates distress, pain and grief in the individual, or resulted from the pain of separation from others and being deprived of the forms of affection that existed among them; Or a lack or shortage of affection and familiarity with others. In 1973 Weiss collected the causes of psycholoneliness in two groups: the first is concerned with the social environment and focuses on the problems and difficulties existing in the social environment of the individual as inevitable causes that lead to psycho-loneliness because of their impact on changing the circumstances of the person; the second is related to individual differences of the person or what is known as the group characteristics, i.e. personality traits that help individuals feel psycho-loneliness (Odat, 2018). While Ashwini(2017) suggests that there are personal variables closely related to the individual's sense of psycho-loneliness, such as low self-esteem, shyness, alienation, boredom, depression, unhappiness. People who suffer from psycho-loneliness are indifferent.

Psycho-loneliness has forms that Young classifies into three forms: (1) transient psycho-loneliness: this includes periods of loneliness, although the individual's social life is marked by harmony and agreement. (2) Transformational psycho-loneliness: the individual has enjoyed good social relations in the recent past, but he feels psycho-loneliness recently due to some new circumstances. (3) Chronic psycho-loneliness: which lasts for long periods of time in which the individual does not feel satisfied with his social relations (Aldalalah, 2018).

\section{The Research Methods}

In order to answer the study questions, the study followed the quantitative approach. It was used the descriptive method and the qualitative approach in order to determine 
the level of nomophobia. The researcher the open interview method to identify the relationship between nomophobia and psycho-loneliness.

\subsection{The population and sample of the study:}

The study noted that the characteristics of the students and the level of their usage and method in the use of cell phones in the secondary stage are similar, so the researcher chose the public and private secondary schools belonging to the Directorate of Education of Irbid as a population to study. Then the schools were selected randomly from (92) secondary schools; the study Instruments were distributed to students in a simple random way (401) male and (599) female students.

\subsection{The study instruments}

The nomophobia scale: In order to detect the level of the fear of telephone loss (nomophobia) among high school students in Jordan, Yildirim (2015) scale was used because of its high internal reliability. The value of the Cronbach alpha coefficient translated by Alukour (2017) to suit the Jordanian environment was 0.95. Apparent validity, factorial validity, validity of construction and the discriminatory validity of the statements have been achieved by being exposed to a group of experts. As for the construct validity, the correlation coefficients for each of the scales were calculated with the total score and the domain to which it belongs, in addition to the arithmetic of the correlation coefficients among the domains and the total score.

Secondly: The construct validity of the second section of the scale (Yildirim scale of nomophobia):

To calculate the reliability coefficient, it was calculated in two ways: Firstly, the stability coefficient calculated by the repetition method of 0.916 .

Secondly, the coefficient of stability calculated by the Cronbach's Alpha method (Internal Cronbach's Alpha coefficient) of 0.92.

The measure is based on the graded rating scale of Likertquinary scale, which is one of the most widely used scales for its easy design, application and correction. According to this measure, the response of the examinee to each of the statements is converted into a weight of between 1-5: the score 1 is given for the "very low" response, 2 for "low", 3 for "medium", 4 for "Great", and finally 5 for "too big".

Psychometric loneliness scale: As for the level of Psycho-loneliness, the study used the Arabic version of the Russell scale (1996) translated into Arabic by Marakshi (2014). The measure in its final image consists of 20 statements that have three alternatives (never, sometimes, always), corresponded by the degrees (1, 2, 3). Aldalalah (2018) verified the validity and stability of its suitability for the Jordanian environment. The scale was presented to a group of arbitrators, experts and specialists with a total of 14 arbitrators. Further, the researcher confirmed the internal reliability that amounted to 0.93 . Cronbach's Alpha reliability coefficient was 0.80 .

Interview instruments: The interview is considered a data collection instrument for individuals and humanitarian groups. The study used the individual interview instrument on the study sample to determine the impact of the position on their learning. The 
interviewers were open-ended, The researcher interviewed four students separately, And he posed an open question to them, what is the effect of neophobia on the level of your learning, the duration of the interview ranged from $10-15$ minutes. These interviews were in a comfortable place, and all the interviews were recorded in audio. While affirming to the students that they are free to refrain from answering the question or to end the interview without providing an excuse. In addition to the confidentiality of the audio recording and did not mention of their names in the study.

\subsection{Study variables}

- Independent variables:

1) Gender (male, female)

2) Specialization (scientific, literary).

3) Type of school (private, government).

- The dependent variables:

1) The level of nomophobia

2) Psycho-loneliness.

\subsection{Data collection and analysis}

The data were collected and classified and then the SPSS program was used. The data were processed using the following statistical methods: Alpha Cronbach coefficient, Pearson coefficient, standard deviation calculation, arithmetic mean, and ANOVA test.

\section{$4 \quad$ Study Findings}

\subsection{The findings of the first question}

"What is the degree of nomophobia among high school students in Jordan? To answer this question, the arithmetical mean and standard deviations of the Yildirim scale statements as explained in the table (1): 
Table 1. The mean and standard deviations of the nomophobia scale

\begin{tabular}{|c|c|c|c|c|}
\hline Rank & Number & Statements & Mean & $\begin{array}{l}\text { Standard } \\
\text { deviation }\end{array}$ \\
\hline 1 & 16 & I am concerned if I cannot access my personal account & 4.23 & 1.978 \\
\hline 2 & 10 & $\begin{array}{l}\text { If I do not have my phone, I'm worried because I cannot contact my } \\
\text { family or friends }\end{array}$ & 4.20 & 1.931 \\
\hline 3 & 5 & The battery life of my phone makes me panic & 4.16 & 2.150 \\
\hline 4 & 15 & $\begin{array}{l}\text { I feel nervous if the contact between me and my family or friends is } \\
\text { broken }\end{array}$ & 4.15 & 1.835 \\
\hline 5 & 7 & I keep checking if I have a data signal or cannot connect to "Wi-Fi" & 4.12 & 1.986 \\
\hline 6 & 9 & $\begin{array}{l}\text { If I do not check my phone for a while I feel a strong desire to exam- } \\
\text { ine it }\end{array}$ & 4.11 & 1.924 \\
\hline 7 & 4 & I feel bad when I cannot use my phone whenever I want & 4.09 & 2.010 \\
\hline 8 & 17 & $\begin{array}{l}\text { I feel uncomfortable if I do not update my account data on the social } \\
\text { networking site }\end{array}$ & 3.96 & 1.973 \\
\hline 9 & 13 & I am worried if I cannot contact my family or friends & 3.94 & 1.951 \\
\hline 10 & 8 & If I cannot use my smartphone I feel like cutting me off somewhere & 3.92 & 1.934 \\
\hline 11 & 11 & $\begin{array}{l}\text { I am concerned that my family or friends have not been associated } \\
\text { with me. }\end{array}$ & 3.90 & 1.937 \\
\hline 12 & 2 & I feel uncomfortable if I do not look at the data through my phone & 3.85 & 1.877 \\
\hline 13 & 20 & I feel eccentric if I do not know what to do & 3.85 & 2.207 \\
\hline 14 & 12 & I am nervous because I am unable to receive text messages and calls & 3.80 & 1.856 \\
\hline 15 & 6 & If the credit card or Internet card is over I feel panic & 3.78 & 2.013 \\
\hline 16 & 19 & I am concerned if I do not see my e-mail & 3.74 & 2.058 \\
\hline 17 & 14 & I feel nervous because I cannot tell if someone tried to contact me & 3.68 & 2.010 \\
\hline 18 & 1 & I feel uncomfortable without getting information through my phone & 3.56 & 2.050 \\
\hline 19 & 18 & $\begin{array}{l}\text { I'm embarrassed because I did not see updates notifications of my In- } \\
\text { ternet connection }\end{array}$ & 3.53 & 1.901 \\
\hline 20 & 3 & The inability to get news (events, weather, etc.) makes me nervous & 3.41 & 1.915 \\
\hline & & Yildirim ometer for Nomophobia & 3.90 & 1.249 \\
\hline
\end{tabular}

Table (1) shows that the mean averages ranged between 3.41 - 4.23. Statement 16, which reads (I am concerned if I cannot access my personal account), came in first place with an average of 4.23, while statement 3 "The inability to get news (events, weather, etc.) makes me moody" came at last and with an average of 3.41. The arithmetical mean of the Yildirim scale for Nomophobia as a whole was 3.90.

\subsection{The findings of the second question}

"Are the average scores of secondary school students in Jordan different on the nomophobia, according to the gender of the student (male, female), the student's specialization (scientific, literary) and the type of school (private, government)?

In order to answer this question, the frequency, percentages, arithmetical means, standard deviations and the quadratic coefficient were extracted from the responses of the study sample members. All of this is explained as below

Firstly: Frequency and percentages according to the variables of the study: The table (2) shows the: 
Table 2. Frequency and percentages according to the study variables

\begin{tabular}{|l|l|c|c|}
\hline & \multicolumn{1}{|c|}{ Categories } & Frequency & Percentage \\
\hline Gender & Male & 401 & 40.1 \\
\hline & Female & 599 & 59.9 \\
\hline Specialization & Scientific & 386 & 38.6 \\
\hline & Literary & 614 & 61.4 \\
\hline School & Government & 775 & 77.5 \\
\hline & Private & 225 & 22.5 \\
\hline
\end{tabular}

Table (2) shows that the percentage of females is higher than that of males, $(40.1 \%)$ for males compared to $59.9 \%$ for females; the percentage of students in the literary branch are higher than that in the scientific branch, $(38.6 \%)$ the scientific branch compared to $(61.4 \%)$ in the literary branch. Further, it shows that the percentage of students in public schools are higher than that in private schools, with $22.5 \%$ of the students of the private schools compared to $77.5 \%$ for those of the public schools. As for the differences in the values of the fields of the scale due to the differences in the general information about the sample of the study, the statistical averages and the standard deviations of the study sample were extracted, as shown in the table (3)

Table 3. Mathematical means and standard deviations of the Yildirim scale according to gender variables, specialization and school

\begin{tabular}{|l|l|c|c|c|}
\hline \multicolumn{1}{|c|}{ Variable } & \multicolumn{1}{|c|}{ Categories } & Arithmetic mean & Standard Deviation & Number \\
\hline Gender & Male & 3.88 & 1.287 & 401 \\
\hline & Female & 3.91 & 1.224 & 599 \\
\hline Specialization & Scientific & 3.99 & 1.100 & 386 \\
\hline & Literary & 3.84 & 1.331 & 614 \\
\hline School & Public & 3.96 & 1.261 & 225 \\
\hline & Private & 3.69 & 1.186 & 225 \\
\hline
\end{tabular}

Table (3) shows an apparent variation in the arithmetical mean and standard deviations, in response to the Yildirim scale and to illustrate the significance of the statistical differences between the arithmetical means, the analysis of the variance of the impact of gender, specialization and the school was used on the Yildirim scale as illustrated by the table (4).

Table 4. Analysis of the variance of the impact of the variables of the sample of the Nomophobia scale

\begin{tabular}{|l|c|c|c|c|c|}
\hline $\begin{array}{c}\text { Source of } \\
\text { variance }\end{array}$ & Total squares & Freedom scores & Squares mean & Fa value & $\begin{array}{c}\text { Statistical } \\
\text { significance }\end{array}$ \\
\hline Gender & 6.253 & 1 & 6.253 & 19.157 & .000 \\
\hline Specialization & 8.831 & 1 & 8.831 & 27.057 & .000 \\
\hline School & 1.984 & 1 & 1.984 & 6.079 & .014 \\
\hline
\end{tabular}


Table (4) shows the following:

- There are statistically significant differences due to the impact of gender, with a value of 30.699 and a statistical significance of 0.000 , and the differences are in favor of females.

- There are statistically significant differences due to the impact of specialization, with a value of 22.581 and a statistical significance of 0.000 , and the differences are in favor of the scientific specialization.

- There are statistically significant differences due to the impact of the school, with a value of 22.581 and a statistical significance of 0.000 , and the differences are in favor of public schools.

\subsection{The findings of the third question}

"Is there a correlation between nomophobia and psycho-loneliness among high school students in Jordan?"

In order to answer this question, the statistical quantitative method and the qualitative approach were followed. The study in the quantitative statistical method obtained the Pearson correlation coefficient as in Table (5).

Table 5. The Relationship between Nomophobia and Psycho-loneliness

\begin{tabular}{|l|l|c|c|}
\hline & & Psycho-loneliness & Nomophobia \\
\hline Psycho-loneliness & Pearson Correlation & 1 & $.766\left(^{* *}\right)$ \\
\hline & Sig. (2-tailed) & & .000 \\
\hline & $\mathrm{N}$ & 1001 & 1000 \\
\hline Nomophobia & Pearson Correlation & $.766\left(^{* *}\right)$ & 1 \\
\hline & Sig. (2-tailed) & .000 & 1000 \\
\hline & $\mathrm{N}$ & 1000 & \\
\hline
\end{tabular}

Table (5) shows that there is a direct correlation between nomophobia and psycholoneliness as Pearson correlation coefficient was .766. This means that the higher the level of nomophobia, the greater the sense of psycho-loneliness. On the contrary, if the level of nomophobia decreases, the feeling of psycho-loneliness decreases.

\subsection{The findings of the fourth question}

Is there an effect of nemphobia on secondary school students in Jordan?

As for the qualitative approach, the study conducted open interviews with the students after preparation for this and after informing them that all their responses are for research purposes only and will be treated with high confidentiality. Their answers came as follows

A female student answered: "Sitting by myself makes me use my cell phone lot, and I spend a long time logging onto social media, that affects of my willingness to learning" while another male student said: "Now, the phone has a very strong effect, because 
when there is a gathering and all the people work on the phone, I feel that it caused a sort of withdrawal among humans. The community is no more than a phone. I see that social life is going to extinction. It's impossible to find a gathering of people and all of them talk to each other. Most of them must carry their phones. No one is listening to anyone. The phone has affected us greatly and it will have a greater impact. And here is the disaster for future generations. It'll cause a state of isolation and introversion for children. We will have a generation that doesn't know what is social relations in addition to feeling shame because they are sticking to telephones. As for me, when I'm in my room by myself, it is impossible for me to leave the phone. Especially after the games that caused addiction to us and influenced our mind. We the grownups, the acute and mindful most of our thinking is how to win the game or the phase of the game. This has become our ambition instead of dedicating our ideas and innovations to a thing that benefits us; we became a group of minds immersed in sleep and thinking only of these games that brought us to Addiction phase, this has an impact on our level of academic achievement and on our overall learning". The response of another student "For me, the phone is effective because I use it very long time and use of the phone increases when I'm alone, and keep awake for very long time which leads to a delay in going to school that affects of my learning level". Another female student answered: "I'm preferred using the phone applications rather than attending a social event. Phone applications make me read and learn new things. I don't think it reduces my social skills but adds to my knowledge store, but it affects of my direct learning skills in the traditional class."

\section{Discussion of the Findings}

The finding showed that the level of nomophobia among high school students was high. This finding can be explained by the fact that students use social networks to gain knowledge of the world and what is going on in it; and what is happening in various scientific, intellectual, political, economic and social fields. Some people see that the provides more experiences, knowledge and values, as well as the love of knowledge, and discussion about study materials and revising them; Connect with people who share interests, colleagues, friends, and family members. Moreover, they believe that the mobile phone re-establishes relationships with old friends. Provides an opportunity for free expression of opinion, dialogue and exchange of ideas; give the opportunity for familiarization with individuals from other countries and different cultures; as well as the development of personal skills and life experiences and dealing with others. Some people use social networks for entertainment, recreation, escaping from family problems and making acquaintances with friends of the opposite gender, making friendships and shopping. Moreover, some social network users consider them an alternative to traditional social life to access cultural, social, religious, national, political places as well as sports, games and entertainment. Social networking sites provide psychological satisfaction to help overcome shyness in students with psychological introversion and social isolation as they open for them new horizons to communicate with others in a virtual world. On the other hand, social networking applications through the phone can help students in self-development, creativity, knowledge enhancement, information 
exchange and increase technical skills. Through the optimal use of social networking sites, the student can reach the maximum amount of knowledge and information useful to him that enhances his ability to academic performance and excellence in the study.

The finding showed the existence of statistically significant differences at the level of $(\infty=0.05)$ for the impact of gender on the scale in favor of females. In other words, females are more likely to have nomophobia more than the males. This study is consistent with the findings of the study by Apearna, Bhavani, Maragatham, 2017; Deniz, Evren, Okan\&Soner, 2017; and Tavolacci, Richard, Dechelotte, \& Ladner, 2015); as well as the study of Muneef, 2014. These studies have shown that females are more likely to be infected with nomophobia than males. This result can be explained by the fact that females are less busy and active than males, as males have a higher freedom of movement and mobility to be more occupied in matters than the mobile phone.

Therefore, females are more connected to mobile phones to fill their free time and to express their activities electronically, making them more likely to get nomophobia. This may be due to the fact that often the applications of social communication through the phone are the outlet for the girl from the pressures inside the house; while the outlet for the young man may be outside the house and where he adjusts his mood. The use of phone applications by females reflects the characteristics of their personalities and the culture of the adolescence stage with all its behavioral implications as a means to prove their self and highlight their personalities. Males use phone applications less than females because they rely on realistic means of communication, not virtual ones, because these means are consistent with the Jordanian social approach that allows males to behave freer than females.

There were statistically significant differences at the level of significance $(0.05)$ for the impact of the track on the scale and for the scientific one; in the sense that the students of scientific specializations are more likely to be infected with nomophobia than those of literary ones. Although there are no previous studies whose findings can be discussed with this finding. This finding can be explained by the fact that students of scientific specializations are more able than students of literary specializations to explore the academic, recreational and social programs and applications in mobile phones, especially smartphones as these phones contain many programs that mostly need mastery of English language; therefore, students of scientific specializations are basically higher of levels than other students of literary specializations in the proficiency of English because their specializations are mostly taught in English. The scientific discipline students need more time and effort than those of the literary ones; hence, the students in scientific specializations are more inclined to resort to mobile phones for entertainment to reduce the pressures they suffer because of the study. They are more inclined to use their phones for the purposes of studying because of their phones academic content and applications, in addition to entertaining themselves because their mobile phones, especially smart phones contain many programs and applications in line with their abilities and tendencies more than those students of literary specializations; furthermore, students of scientific specializations are most often more serious and take most of the things seriously. Therefore, their reactions are greater and severer. In addition, the students of scientific specializations are more likely to develop nomophobia. 
There were statistically significant differences at the level of significance (0.05) of the impact of the school on the scale and in favor of public schools; in the sense that students in public schools are more likely to be infected with nomophobia than students in private schools. Although there are no previous studies whose findings can be discussed with this finding, this finding can be explained by the fact that public schools have larger numbers of students compared to private schools. The composition of students in public schools is more variation in the nature of students in terms of income levels, and student accommodation, in the sense that the number and composition of students in public schools are more numerous and varied than that in private schools. Thus, students in public schools are more interested in establishing relationships with other students, These relationships, increase the use of the mobile phones to communicate and interact, especially through social media such as Facebook, twitter, what's up, and snap chat, and various online chat with their acquaintances, colleagues and friends. Therefore, students of public schools more linked to their phones than students of private schools for because their numbers are bigger and much more diverse than those of private school students; hence, the chances of public school students becoming more infected with nomophobia are greater than those for private school students.

This finding can be attributed to the fact that smart phones have electronic services that take the user out of the reality in which he lives into an electronic world where he can see what he wants from around the world; in addition to using smart phone applications of social communication and the Internet that increase the rates of unsociability, loneliness, depression and reduce the social contributions with the result the individual becomes socially isolated despite living among people. Social communication applications through the phone affect face-to-face personal communication and affect the interaction of users with their families, relatives and friends,; leading to a noticeable withdrawal from social interaction which leads to a sense of psycho-loneliness. The nature of the applications of social communication through the phone, including features and characteristics such as ease of use, as an example.

It is enough for the individual to have the basic skills in these applications and the Internet to be able to enter this open virtual society. This allows users to communicate, interact and create new relationships, and share common interests. These features of smartphones attract the user (student) and isolate him from the real social environment because the user under the impacts of these applications is unaware of the time he spends using them. He is found making comments and publishing images and videos to his default friends to make them aware of any updates; as well as he follows them, and tells them of what he does and even he informs them of his psychological condition in addition to chatting and making relationships. All of this makes the student unaware of the time spent in using these applications; hence, there is less real individual social interactions because of compensation through interactions via a technical medium.

Despite the merits of these interactions, they may lead the individual to psycho-loneliness that appears due to a lack of interactivity with others; where virtual relationships through the applications of social networking sites via the phone lack the depth and warmth of the real social relations. Ritual reality relations and friendships are rarely strong and non-fake. Many people hide their real identity during the communication or mention misleading data about them, which results in the formation of false relations 
that lack continuity and duration. Most of these relations are superficial and short. Therefore, the student feels psycho-loneliness even under these virtual relations because they do not live up to the level of real relationships provided by sincere feelings resulting from constant mingling and direct communication; therefore, virtual relationships fail to satisfy the need that the individual wants. Further, this condition can be attributed to the fact that students in secondary school live periods of great psychological stress because of the importance of this stage in their lives, which requires long study hours that isolate the student from the real social environment; hence, he finds the applications of social communication through the phone in his hands a way out of these pressures and compensation for the real social relations other virtual ones.

\section{Conclusions}

This study purports that nomophobia, can be measured a contemporary age phobia introduced to our life with the rapid deployment and adoption of smartphones. Through this study, nomophobia is defined as the fear of not being able to make use of a smartphone or the Applications. It refers to the fear of not being able to communicate, losing the connectedness that smartphones allow, not being able to access information through smartphones, and loss of services provided by smartphones.

This study found statistically significant differences between the averages of the students' estimates on the scale of nomophobia due to the gender variable for females; differences that can be ascribed to specialization in favor of scientific specialization and variable related to the impact of the school in favor of the students of public schools. Moreover, the findings showed a positive relationship between the averages of nomophobia and psycho-loneliness among students.

\section{$7 \quad$ Recommendations and Proposals}

In the light of the findings, the study recommends the following:

1. Building awareness programs targeting groups with a high level of nomophobia.

2. Thinking of a specific mechanism in the process of building a university course on educating university students about such cases, or perhaps including such ideas in the general courses (university requirements)

3. Conducting further studies on the subject of the study by applying it to faculty members in public and private universities.

4. Conducting further studies on the subject of the study by applying it to students of various stages in educational institutions. 


\section{$8 \quad$ References}

[1]Abreem,S. (2015). The Relationship between Internet Addiction and the Sense of Psychological Alienation (A Field Study in a sample of Umm Al - Boaqi University Students and Students). Journal of Human and Social Sciences, 15, 215-240.

[2]Abu Mandi, W. (2016). Behavioral problems and their relationship to family communication among adolescents Smart phone users from the point of view of parents. Unpublished Master Thesis _ Islamic University / Gaza.

[3]Aitan, T. (2017). The sense of psychological loneliness and its relationship with the addiction of Internet use by a student of Shakra University. Al-Shamal Journal of Human Sciences, 2 (2), 167-202. https://doi.org/10.12816/0037201

[4]Al Tarawneh, N \& Nafikh,L. (2014). The Use of the Internet and its Relationship to Academic Achievement, Social Adjustment, Depression, and Communication Skills among Qas-sim University Students. The Islamic University for Educational and Psychological Studies, 26(4),283 - 331.

[5]Al-Ahmari, F. (2014). The impact of the use of modern means of communication on family dialogue: mobile phone and the Internet. Unpublished Master Thesis, King Saud University.

[6]Aldalalah, O. (2018. (The Level of Cyber-bullying (bully, victim) through Smartphone Applications among Students of the Faculties of Education in Jordanian Universities and its Re-lation to Loneliness.International Journal of Social Sciences \& Educational Studies, 5(1), 145 - 163. https://doi.org/10.23918/ijsses.v5i1p145

[7]Alkour, S. (2017). The fear of phone loss (Neemophobia) among Yarmouk University students. Unpublished Master Thesis, Yarmouk University.

[8]Aparna, S., Bhavani, U. \& Maragatham, S. (2017). NOMOPHOBIA - An Insight into Its Psychological Aspects in India.The International Journal of Indian Psychology, 4(2), 5-15.

[9]Ashwini, A. (2017). Effect of Loneliness on Self Esteem of High School Boys and Girls. The International Journal of Indian Psychology, 5(1), 5 - 11.

[10]Ben Dahnoun, S. \& Mahi, I. (2014). The sense of psychological loneliness and its relation to self-esteem among university students. Journal of Human and Social Sciences, 16, 69-86.

[11]Bivin, J., Preeti, M., Praveen, C., \&Thulasip, P. (2013) .Nomophobia Do We really need to worry about. Reviews of Progress, 1(1), 1-5.

[12]Dahshan, M. (2013). Use mobile phone to teach between support and rejection. A paper presented to the Second Scientific Symposium Higher Education Systems in the Competitive Age, Unpublished Master Thesis, Menoufia University.

[13]Darcin.A., Kose, S., Noyan, C., Nurmedov, S.,Yılmaz, O \& Dilbaz, N. (2016). Smartphone addiction and its relationship with social anxiety and loneliness.Journal Behaviour\& Information Technology, 35(7), 520-525. https://doi.org/10.1080/0144929X.2016.1158319

[14]Dardera, A. (2018). Neophobia: phobia of smart phones and its relationship to sensory research and social anxiety. Exploratory study.Psychological Studies, 26(3), 361 - 392.

[15]Degrere, A. ( 2017). Relationship between addiction of social networks and the Depression, Social Anxiety, a Psychological Loneliness.Journal of Humanities and Social 1 (1), 89-110.

[16]Gezgin, D., Sumuer, S., Arslan, O \&Yildirim, S. (2017). Nomophobia Prevalence among Pre-service Teachers: A case of Trakya University. TrakyaÜniversitesiEğitimFakültesiDergisi, 7(1), 86 - 95. 
[17]Holohan, M. (2015). Smartphone separation anxiety: How bad is your nomophobia? Retrieved May, 14, 2018, from http://www. Today.com/series/wired/smartphone-separationanxiety-how-bad-yours-t20786.

[18]King, A., Valenca, A., Silva, A., Sancassiani, F., Machado, S. \&Nardi, A. (2014). Impact of Cell Phone Use Interfering with Symptoms and Emotions of Individuals with Panic Disorder Compared with a Control Group. Clinical practice andepidemiology in mental health: CP \& EMH, 10, 28-35. https://doi.org/10.2174/1745017901410010028

[19]Lee, Y., Chang, C., Lin, Y \& Chang, Z. (2014). The dark side of smartphone usage: Psychological traits, compulsive behavior and techno stress. Computers in Human Behavior, 31, 373-383. https://doi.org/10.1016/j.chb.2013.10.047

[20]Marakshi, M. (2014). The use of social networks and their relationship to the sense of Psycho-loneliness among university students (Facebook model). Unpublished Master Thesis, University of Mohammed Khaidr

[21]Mauludi, M. (2016). Keterkaitan Internet Addiction Dan NomophobiaDenganAyat-Ayat AL-Qur'an PerspektifMufassir Indonesia (Doctoral dissertation ), UIN SunanAmpel Surabaya, Indonisia.

[22]Melhem, M. (2010). The sense of psychological loneliness and its relation to the five factors of the personality A field study on a sample of students of Damascus University. University of Damascus Journal, 26 (4), 625 - 668.

[23]Muflah, M., El-Hersh, A., Ababneh, Z., Aldalalah, O. (2010) .The Effect of Psychological, Healthy and Social of Using the Internet from Teachers Perspectives.Journal of Educational \& Psychological Sciences, 11(3), 287 - 313. https://doi.org/10.12785/JEPS/110310

[24]Neelima S., Pooja S, ,Neha S , \&Wavare, R. (2015). Rising concern of nomophobia amongst Indian medical students.International Journal of Research in Medical Sciences, 3(3), 705707. https://doi.org/10.5455/2320-6012.ijrms20150333

[25]Neerab, Nesreen. (2016). The sense of Psycho-loneliness and the relative value of the social networking sites of the students in the governorates of Gaza. Unpublished Master Thesis, Is-lamic University-Gaza.

[26]Nuri, H\& Kohan, Z. (2016). The comparison of loneliness and spirituality well being in married men with and without extramarital involvement. International Journal of Educational and Psychological Researches, 3(2), 154-158. https://doi.org/10.4103/2395-2296.180304

[27]Odat, W. (2018). Developing the Nomophobia Scale for Jordanian Universities Students. Unpublished Master Thesis, Yarmouk University.

[28]Pavithre, M, Madhukmar, S \& Murthy, M.(2015). Study on nomophobia -mobile phone dependence, among students of a medical college in Bangal. National journal of community medicine, 6(2), 340-344.

[29]Ranaei, S., Taghavi, M \& Goodarzi, M. (2016). The Effect of Loneliness on Social Networking Sites Use and Its Related Behaviors.Global Journal of Health Science. 8(8), 162-171. https://doi.org/10.5539/ghhs.v8n8p162

[30]Rokach, A. (2004). Loneliness Then and Now: Reflections on Social and Emotional Alienation in Everyday Life. Current Psychology: Developmental _9 Learning _9 Personality * So-cial 23(1), 24-40. https://doi.org/10.1007/s12144-004-1006-1

[31]Shaheen, M. (2015). The Effectiveness of a cognitive-behavioral counseling program to reduce Internet addiction among a sample of university students.Al - Aqsa University Journal (Human Sciences Series) 19 (2), 358 - 390. https://doi.org/10.12816/0018044 
[32]Shatat, F., Aldalalah, O., \&Ababneh, Z. (2017). The Impact of E-book on Levels of Bloom's Pyramid at ECT Studants in Light of the Internal and External Motivation to Learn Mathematics and Statistics. Asian Social Science, 13(2), 49-63. https://doi.org/10.5539 lass.v13n2p49

[33]Tavolacci, M., Meyrignac, G., Richard, L., Dechelotte, P., \& Ladner, J. (2015). Problematic use of mobile phone and nomophobia among.European Journal of Public Health, 25 (3), https://doi.org/10.1093/eurpub/ckv172.088

[34]Vanhalst, J. (2012). Loneliness in Adolescence:Developmental Course, Antecedents, and Consequences. KatholiekeUniversiteit Leuven.

[35]Wei, M., Russell., D \&Zakalik, R. (2005). Adult Attachment, Social, Self-Efficacy, SelfDisclosure, Loneliness, and Subsequent Depression for Freshman College Students: A Longitudinal Study. 52( 4), 602-614. https://doi.org/10.1037/0022-0167.52.4.602

[36]Yildirim, C. (2014). Exploring the dimensions of Nomophobia: Developing and validating a Questionnaire using mixed methods research. Unpublished Master Thesis, Iowa State University.

[37]Yildirim, C., Correia, A. (2015). Exploring the dimensions of nomophobia: Development and validation of a self-reported questionnaire. Computers Human Behavior, 49, 130-137. https://doi.org/10.1016/j.chb.2015.02.059

[38]Zaqout, M. (2011). The identity of the self and its relation to the assertion and Psycho-loneliness of the unknown. Unpublished master thesis, Islamic University, Gaza

\section{$9 \quad$ Author}

Dr. Osamah (Mohammad Ameen) Aldalalah is an Associate Professor in Educational Technology. Taibah University, Madina, KSA and a researcher in education technology and multimedia. E-mail: odalalah@taibahu.edu.sa

Article submitted 2019-12-17. Resubmitted 2020-02-14. Final acceptance 2020-05-16. Final version published as submitted by the authors. 